\title{
Assessing Barriers of Growth of Food Processing SMIs in Malaysia: A Factor Analysis
}

\author{
Syed Shah Alam (Corresponding author) \\ School of Management, Faculty of Economics and Management \\ National University of Malaysia \\ E-mail: shahalam@ukm.my \\ Mohd Fauzi Mohd Jani \\ School of Management, Faculty of Economics and Management \\ National University of Malaysia \\ E-mail: mdfau@ukm.my \\ Zizah Che Senik \\ School of Management, Faculty of Economics and Management \\ National University of Malaysia \\ E-mail: zizahcs@ukm.my \\ Ahmad Khairy Ahmad Domil \\ School of Management, Faculty of Economics and Management \\ National University of Malaysia \\ E-mail: khairy@ukm.my
}

This project is financed by the National University of Malaysia.

\begin{abstract}
The aim of this research is to examine barriers of food process based small and medium scale manufacturing firms' growth in Malaysia. We argue that along the process, the SMIs might encounter issues with internal and external environments, institutional, availability of both tangible and intangible resources, organizational and managerial and others that most likely will affect the growth of the firms. From the analysis it was found that there are various factors that could prevent the food processed based SMIs to grow. The findings will contribute to the growth and development of the SMIs in particular in the food processing industry. The paper finalizes with some conclusions for policy makers, industry and other actors, and also future research.
\end{abstract}

Keywords: Growth, Food processing SMIs, Malaysia, Barriers

\section{Introduction}

Food processed based small and medium Enterprises (SMEs) has been recognized as one of the most important contributors for the economic development of many countries (Lamprinopoulou \& Tregear, 2006). According to Malaysian-German Chamber of Commerce \& Industry (MGCC), predominantly the number of Malaysian-owned food processing SMEs has increased from 45,418 in 2007 to 44,778 in 2008. This industry has contributed about $10 \%$ of the Malaysian manufacturing output and increased job creation by $1.4 \%$ (MGCC, 2010). In the food processing segment, $80 \%$ of the total numbers of establishments are SMEs. The main sub sectors are the food processed industry including fish and fish products, livestock and livestock products, fruits and vegetables, and cocoa-based products. The processed food products have become the choice of many Malaysians due to the increasing trend of their standard of living and purchasing power. The changes of Malaysian lifestyle have resulted to an increase in the demand for convenience food and health food which in turn has led to more establishments of food-processed based SMEs in the country.

Over last few decades, research on SMEs development has concentrated in various disciplines, such as economics, strategy, psychology, network and innovation. Nevertheless, research on small firm growth is still limited (Davidsson \& Wiklund, 2000; Wiklund, Patzelt \& Shepherd, 2009; Zhou \& Wit, 2009). According to Zhou and Wit (2009) the 
existing literature is highly fragmented. For example, Begley \& Boyd (1987) focused on the behaviour of the entrepreneurs, Smallbone et al. (1995) and Constantinides (2004) concentrated on strategy of growth; whereas Audretsch et al. (2004) focused on the relation between growth and firm size. To our understanding, none of them has exclusively focused on the determinants and barriers of growth of firm in the food industry. Therefore, this current research will identify the barriers to growth in the food-processed SMIs in Malaysia.

\section{The Malaysian SME Food Industry}

Small and medium Enterprises (SMEs) represent majority of the business in Malaysia, constituting $99.2 \%$ of total establishments in the country, and providing about $56 \%$ of the total workforce. Food industry has a major socioeconomic importance in Malaysia. In total, the establishment of the food processing sector is 6,069 in which $5,925(98 \%)$ are the SMEs. The processed foods are exported to more than 80 countries, with annual export value of more than RM6 billion (approximately US $\$ 1.7$ billion), amounting to two-thirds of the total Malaysian food exports (The Busy Times, 2010).

The Malaysian SMEs in the food sector are driven to operate to contribute to household income, for self-employment and the growing demand of international markets in particular for halal foods (SMIDEC, 2007). This industry has a great potential to expand globally because of the increasing awareness of halal products consumption among the consumers. As reported by the Small and Medium Industries Development Corporation (SMIDEC, 2007) several factors affected the growth of SMEs in the food industry including:

- $\quad$ increasing value of halal markets, estimated at USD547 billion a year,

- $\quad$ substantial number of global Muslim population, approximately 3 billion, or $30 \%$ of the total world population,

- potential market of in the Asian region, amounting USD3.7 billion,

- expansion of consumers including the non-Muslims.

- similarity of the taste of products in particular among the middle east nations and neighbor countries,

- increase of disposable income and buying power among Muslim countries such as Middle East, West Asia,

North Africa, Europe and North America,

- $\quad$ effect from the economic integration, such as AFTA.

In addition, Malaysia, foresees that there is great potential for developing and promoting halal products for the global markets. Therefore, the Malaysian government has formulated policy and supports in the national plans to assist SMEs in the food industry through its ministries such as Ministry of Entrepreneurship and Co-operation (MECD), Malaysian Agricultural and Development Institute (MARDI), Federal Agricultural Marketing authority (FAMA), and SME Corp (IMP3, 2006; Ninth Malaysia Plan, 2006). Each one of this institution plays significant role to assist the food-processing SMEs by:

- $\quad$ ensuring the availability of raw materials,

- expanding and diversifying food processing activities and promoting the growth of the targeted areas,

- enhancing the competitiveness of and increasing the exported food products globally,

- $\quad$ intensifying R\&D

- $\quad$ strengthening human resources development,

- $\quad$ strengthening the institutional supports for further development of the industry.

Despite the supports received from many, the food industry in Malaysia has been facing some setbacks of growth. As this industry deals with various stakeholders throughout the food chain starting with farmers or fishermen to the suppliers, policy-makers, productions, manufacturers, transportation services, retailers, wholesalers, caterers and consumers (Talib and Ali, 2009), the food processing SMEs will face with micro and macro difficulties and challenges. Menrad (2003) argues that the process might affect the total chain of far-reaching technical and economic changes in the production and processing of food, as well as in society, thus affect the growth of the firms in this industry.

Consequently, looking at the growth of SMEs in the food industry in Malaysia context, we foresee that the chain of processing food products have significant impacts on the entire processing chain of agricultural production, and food processing up to the distribution of food to end consumers. We argue that along the process, the SMEs might encounter issues with internal and external environments, institutional, availability of both tangible and intangible resources, organizational and managerial and others that most likely will affect the growth of the firms. Therefore, this current research will identify the barriers to growth in the food-processed SMIs in Malaysia. The main purpose of this paper is to examine the determinants that influence the growth of Malaysian SMEs in the food industry and to identify 
the most important variables affecting the growth. The findings will contribute to the growth development of the SMEs in particular in the food processing industry. The paper finalizes with some conclusions for policy, industry and other actors, and also future research.

\section{Literature Review}

Some studies describe factors thought to influence SMEs growth. The main factors that influence on growth of SMEs are strong need of achievement, availability of financial capital Zhou and Wit (2009); behaviour, personality, attitude (Storey, 1994), their capabilities, including education and training that create higher expectations in some industry sectors (Henry et al., 2005), and their social capital which influences access to resources (Brush et al., 2004). Secondly, Storey (1994) also identified previous management experience, family history, functional skills and relevant business sectors knowledge as the major determinants for SMEs growth.

While the aforementioned determinants generally help firm growth, there are also factors that inhibit firms growth (Davidsson, 1989). These factors are considered as growth barriers. Most of the SMEs are more like face problem when they enter into the business and also when they are growing compare to the large business. Commonly addressed barriers for small businesses include institutional barriers and financial barriers (Zhou and Wit, 2009). Institutional barriers are mainly discussed with the focus on firms' interaction with government, including legalization, taxation, and government support amongst others. Davidsson and Henreksson (2002) studied from both theoretically and empirically and strongly argue that certain institutions intentionally discriminate against the growth of SMEs which in turn act as a growth barrier. It is not difficult to imagine that SMEs would have a tough period when they face unfavourable tax system, discriminatory regulations and complicated laws.

Financial barriers represent lack of financial resources. Becchetti \& Trovato, (2002), Pissarides, (1998), Riding \& Haines, (1998) have been argued that credit constraints, lack of external debt, and equity capital are the main obstacles to the growth of SMEs. Evidence suggests that banks are more conservative when they provide loans to SMEs. According to Stiglitz and Weiss (1981) SMEs are more likely to be charged relatively high interest rates and asked for high collateral and loan guarantees. Furthermore, SMEs could also face external barriers, internal organizational barriers and social barriers which cover aspects of market position of a firm, access to qualified human capital, and access to network (Bartlett and Bukvic, 2001).

Biljana Acevska (2009) studied on Macedonian SMEs found some barriers inhibit their growth in business. The study reveals that the most prominent institutional problems related to start-up enterprises were the difficulties in acquiring the necessary documents from state institutions and their bureaucratic procedures. The main obstacles to growth were associated more with the general economic climate and included high taxes, high interest rates and a lack of demand for the product. This study also indicated in their research, the lack of finance and the high costs of investment capital are particularly acute problems in spite of the efforts which have been made to alleviate them. The most important social barriers are the lack of support from the state; the lack of trust in society (the economy) the lack of support from the Chamber of Commerce; inadequate information on finance; and inadequate information on the market. The main internal barriers found in that survey was low quality of equipment.

In Malaysia, several setbacks affecting the SMEs growth suggested by Hashim and Ahmad (2005) focus mainly on the internal aspect in term of resources such as human resource, marketing, operations and production, financial and strategic planning of the enterprises. A qualitative study by Senik (2010) on internationalization of Malaysian SMEs reveals that, governmental policy related barriers including lack of standardization, lack of transparency, incompetent implementations, mindsets of policymakers, regulations related barriers including long procession time, bureaucracy, firm capability related barriers including resources, production capability, managerial capability and political barriers including interference, protocol and personal-interest are major internal barriers hinders SMEs growth in the global market.

\section{Research Methods}

\subsection{Sample and data sources}

Consistent with other studies on small and medium sized-firms in the entrepreneurship literature (Baird, Lyles and Orris, 1994; Hodgetts and Kuratko, 1998; Beamish 1999; Wolff and Pett, 2000), this study employs the definition of SMEs provided by the National SME Development Council (NSDC), "an enterprise with annual sales turnover not exceeding RM25 million or full time employees not exceeding 150 employees (NSDC, 2005, p. 5). Following the definition of an SME, we referred to the SMIDEC directory to identify potential respondents in the food processing industry in Malaysia. Our focused area is the SMIs in Klang Valley which is located in the central part of Malaysia.

We utilized a quantitative methodology using a survey questionnaire. The survey instrument packages consisting of a cover letter and a set of questionnaire were mailed to $500 \mathrm{SME}$ food processing companies from April to June 2010. 
The contact person identified was either the owner of the business or a top-level manager in the organization. After a week of the initial mailing, we personally contacted our selected respondents over telephone to request their participation in the survey. In this process, some respondents agreed to be interviewed personally. We hired enumerators who went to the premises to collect the questionnaire once we received confirmation that the SMI owners agreed to provide response to the questionnaire. To ensure that the questionnaires were answered by the SMEs representative themselves, we requested our enumerators to collect their business cards or to get the company's endorsement.

At present a total of 170 completed questionnaires were received, indicating $34 \%$ of response rate. However, we discarded four sets of questionnaires due to incomplete responses which unable us to analyze. In total, 166 completed questionnaires were used for analysis. All the data were recorded in the excel program, which later the file was transferred into SPSS to conduct the analysis.

A profile of the responding companies is shown in Table 1 . The majority of the surveyed SMIs in regards to the business area are others (27.1\%), while $19.3 \%$ are fruits and vegetables, $16.3 \%$ are livestock product, $15.1 \%$ fish and related products, $14.5 \%$ are agri-bio products and only $7.8 \%$ are palm oil products. A slight majority of the surveyed SMIs (47.6\%) had been in business for a period of five to ten years. While not a single SMIs ( $0 \%$ of the sample) have been in business for less than 1 year, $18.7 \%$ SMIs were in business for one to five years.

The results indicate that most of the respondents were on graduate with over $60 \%(63.9 \%)$ holding high school, college or diploma degrees. The majority of them were Chinese (53.0\%), while only one-third of the respondents were ethnic Malay (31.3\%) and Indian (9.6\%) only.

\subsection{Instrument Development}

To identify which factors have a significant influence on the growth of food processed based SMIs in Malaysia, we developed a survey questionnaire to collect information from SMIs owner or manager. The research process for this study includes four main steps:

1) formulation of research problems, which includes reviewing related literature, understanding correspondent contents of SMEs growth and formulating research propositions;

2) questionnaire development, which includes selecting items for questionnaire, designing survey questionnaires and then interviewing academics and practitioners in SMEs or entrepreneurs area;

3) data collection and analysis, including survey administration and data collection, factor analysis and reliability test; and

4) identification of those factors which influence SMIs' growth.

The respondents were requested to indicate, using a five-point Likert scale $(1=$ very low barrier, to $5=$ very high barrier), the extent to which they found barriers of those statements on growth. A pilot test was conducted first by asking some owners and managers to answer the questionnaires. 50 samples were collected. After we interviewed respondents and analyzed these samples, minor modification was made to the measurement instrument,

\section{Results}

We conducted a correlation analysis in order to find out whether these items are fit to factor analysis. The result showed that the 31 items are correlated with each other. Furthermore, most correlation coefficients are over 0.3 and these coefficients are statistically significant at the significant level of 0.05 . So, the following step is to conduct an exploratory factor analysis (EFA) to assess the 31 measurement items. The result shows that the Kaiser-Myer-Olkin (KMO) value is 0.775 , more than 0.7 , which also means that these items are satisfied to do exploratory factor analysis (Malhotra, 1999).

The initial factor solution resulted in six factors with eigenvalues higher than unity. The five factor solution for the 31 items accounted for $50.09 \%$ of the variance. Table 3 shows a purified list of 31 items with a clear factor structure in five factors from EFA. The cumulative contribution to total variance explained is $50.089 \%$.

The eigenvalues and contribution percentage of the five factors (expressed by y1, y2, y3, y4, y5 respectively) are shown in Table 3. The rotated component matrix by varimax with Kaiser normalization is as follows. The results of a reliability test and an item-total correlation analysis also showed that the derived factors are reliable. The reliability coefficient alpha values of the five factors are high with 0.77 for institutional barriers, 0.83 for internal barriers, 0.77 for external barriers, 0.89 for financial barriers, and 0.78 for social barriers, exceeding the benchmark of 0.70 for exploratory research (Nunnally and Bernstein, 1994).

The six identified factors are summarized as follows. 
- $\quad$ Factor 1: financial barriers $(y 1)$ accounts for $21.259 \%$ of the total explained variance and consists of seven items.

- $\quad$ Factor 2: institutional barriers (y 2) accounts for $10.918 \%$ of the total explained variance and consists of eight items.

- $\quad$ Factor 3: institutional barriers (y3) accounts for $7.480 \%$ of the total explained variance and consists of seven items.

- $\quad$ Factor 4: social barriers (y4) accounts for 5.629\% of the total explained variance and consists of five items.

- Factor 5: external barriers (y5) accounts for $4.802 \%$ of the total explained variance and consists of four items.

\section{Discussion and conclusion}

The above analysis manifests that financial barriers have the most important impact on the SMIs growth, meaning that higher the financial barriers the lower the growth of food processed based SMIs in Malaysia. It is expected since past literature has consistently shown that financial barriers are main barriers for SMEs growth (Zhou and Wit, 2009; Becchetti \& Trovato, 2002; Pissarides, 1998; Riding \& Haines, 1998). This finding suggests that high collateral requirements, bank charges, bank bureaucracy, banks ignoring loan proposal, time consuming loan disbursement, costly preparation of a business plan and refusal of bank finance are the major concern to the decision makers and policy makers about the SMIs management.

This research therefore further proves the earlier findings that showed, institutional barriers are the second most inhibitor for SMIs growth in Malaysia. Studies like those carried out by Zhou and Wit, (2009) and Biljana Acevska (2009) have generally shown that bureaucracy, license refusal and public procurement regulations are the main institutional obstacles to growth of SMEs.

The following important factor is internal barriers. This research therefore further proves the earlier findings that showed internal barriers are not serious barriers to grow SMIs in Malaysia (Biljana Acevska, 2009).

The other two factors - external barriers and social barriers - have relative small influences on SMIs growth, which means that the SMIs owner or manager have a very poor knowledge of external and social factors, and that public education on the social matters is not quite enough.

The purpose of this study is to examine the important barriers that affecting growth of food processed based SMIs in Malaysia. Taking all these into consideration, it is easy to understand the main barriers, as well as the non-supporting tendency of financial institutions for growing SMIs in Malaysia. From a managerial viewpoint, the findings provide support for investment decisions, and for decisions relating to the growth of SMIs that address and take the concerns and needs of companies into consideration. As Malaysian government, growth of food processed based SMIs in importance and priority for business worldwide, an understanding of the barriers that influence SMIs growth is invaluable.

\section{Limitation}

Although valuable information has emerged through the gathering of data and measurement of the major barriers of growth, the sample is not yet large enough as compared to the total of 45,418 food and beverages SMIs in whole Malaysia in order to draw any conclusive analysis on the results. Another limitation of this study is in term of location whereby it is focusing on one specific place (Klang Valley in Malaysia). In addition, it is suggested that any similar study in the near future should measure the potential growth of food processed SMIs and examine if the barriers of growth has been overcome. Also, there is a need for more in-depth studies and analysis focusing on a specific area with regard to growth.

\section{References}

Acevska, B. (2009). Entrepreneurship under difficult circumstances: factors hindering SME growth in the Republic of Macedonia, South-East Europe Review S. 109 - 122.

Audretsch, D. B., Klomp, L., Santarelli, E. \& Thurik, A. R. 2004. Gibrat's law: are the services different? Review of Industrial Organization, 24: 301-324.

Becchetti, L. \& Trovato, G. 2002. The determinants of growth for small and medium sized firms: the role of the availability of external finance. Small Business Economics, 19(4): 291-306.

Begley, T. M. \& Boyd, D. P. (1987). A comparison of entrepreneurs and managers of small business firms. Journal of Management, 13: 99-108. 
Bartlett, W. \& Bukvic, V. 2001. Barriers to SME growth in Slovenia. MOCT-MOST: Economic Policy in Transitional Economies, 11: 177-195.

Brush, C., Carter, M.N., Gatewood, J.E., Greene, G.P. \& Hart, M. (2004), Clearing the Hurdles: Women Building High Growth Businesses, Financial Times - Prentice Hall, London,

Constantinides, E. (2004). Strategies for surviving the Internet meltdown, Management Decision, Vol. 42, No. 1, pp.89-107.

Davidsson, P. (1989). Continued Entrepreneurship and small firm growth. Stockholm School of Economics,Stockholm.

Davidsson, P. B. Kirchhoff, J.A. Hatemi, \& Gustavsson, H. (2002). Empirical Analysis of Business Growth Factors Using Swedish Data, Journal of Small Business Management, Vol. 40, No. 4, pp.332-349.

Davidsson, P. \& Henreksson, M. (2002). Institutional determinants of the prevalence of start-ups and highgrowth firms: evidence from Sweden. Small Business Economics, Vol. 19, No. 2, pp.81-104.

Davidsson, P. \& Wiklund, J. (2000). Conceptual and empirical challenges in the study of firm growth. In D.

Hashim, M.K. \& Ahmad (2005). Exploring the Management Problem Areas in SMEs. In Small and Medium-sized Enterprises in Malaysia: Problems and Prospects, (ed) Mohd Kahiruddin Hashim, Universiti Utara Malaysia Press. ISBN 983-3282-57-1

Henry, C., Hill, F. \& Leitch, C. (2005). Entrepreneurship education and training: can entrepreneurship be taught?, Journal of Education and Training, Vol. 47 No.2, pp.98-111.

IMP3 MITI. (2006). IMP3: Third Industrial Master Plan 2006-2020 Malaysia-Towards Global Competitiveness. Percetakan National Malaysia Berhad, Ministry of International Trade and Industry Malaysia, Kuala Lumpur, Malaysia.

Malaysian-German Chamber of Commerce \& Industry, Market Watch 2010 - The Food Industry, available at: http://malaysia.ahk.de/fileadmin/user_upload/Dokumente/Sektorreports/Market_Watch_2010/Food_2010_ENG_.p df, dated. 01 August, 2010.

Menrad, K. (2004). Innovations in the food industry in Germany. Research Policy, Vol. 33, pp. 845 - 878.

Ninth Malaysia Plan. (2006). Ninth Malaysian Plan 2006-2010. Putrajaya, Malaysia: Economic Planning Unit, Prime Minister's Department Malaysia. Available at www.epu.gov.my/.

NSDC. (2005). Definitions For Small and Medium Enterprises in Malaysia (Approved for adoption by National SME Development Council on 9 June 2005), Available at www.smeinfo.com.my/pdf/sme_definitions_ENGLISH.pdf.

Pissarides, F. (1998). Is lack of funds the main obstacle to growth? The EBRD's experience with small and medium-sized businesses in central and eastern Europe: European Bank for Reconstruction and Development.

Riding, A. L., \& Haines, G. J. (1998). Defaulting on loan guarantees: costs and benefits of encouraging earlystage growth, In R. P. D. Bygrave, W. D. Bygrave, N. M. Carter, S. Manigart, G. D. Meyer, \& K. G.

Senik, Che, Z. (2010). Models, Processes, and Factors Influencing Internationalisation: The Case of Malaysian SMEs. Can be accessed via: http://wwwlib.murdoch.edu.au/adt/pubfiles/adt-MU20100309.122732/02Whole.pdf.

Smallbone, D., Leigh, R. \& North, D. (1995). The Characteristics and Strategies of High Growth SMEs, International Journal of Entrepreneurial Behaviour and Research, Vol. 1, No. 3, pp.44-62.

SMIDEC. (2009). SME Performance Report 2008. Small and Medium Industries Development Corporations (SMIDEC), Kuala Lumpur, Malaysia.

Stiglitz, J. E. \& Weiss, A. (1981). Credit rationing in markets with imperfect information. American Economic Review, Vol. 71, No. 3, pp.393-410.

Storey, D. (1994). Understanding the Small Business Sector, Rutledge, New York.

Talib, H. A. \& Ali, K. A. (2009). An overview of Malaysian food industry: the opportunity and quality aspects. Pakistan Journal of Nutrition, Vol. 8, No. 5, pp.507 -517

Wiklund, J., Patzelt, H. \& Shepherd, D.A. (2009). Building an integrative model of small business growth, Small Business Economics, Vol. 32, pp. 351-74.

Zhao, H. \& Wit Gerrit de (2009). Determinants and dimensions of firm growth, Scientific Analysis of Entrepreneurship and SMEs, pp. 3-34. 
Table 1. Demographic profile and descriptive statistics

\begin{tabular}{|c|c|c|c|}
\hline Respondents' Characteristics & & Frequency & Percentage \\
\hline Business areas & $\begin{array}{l}\text { Palm oil products } \\
\text { Livestock products } \\
\text { Fish and related products } \\
\text { Agri-Bio products } \\
\text { Fruits and vegetables products } \\
\text { others }\end{array}$ & $\begin{array}{l}13 \\
27 \\
25 \\
24 \\
32 \\
45\end{array}$ & $\begin{array}{c}7.8 \\
16.3 \\
15.1 \\
14.5 \\
19.3 \\
27.1 \\
\end{array}$ \\
\hline Years in business operation & $\begin{array}{l}\text { Less than } 1 \text { year } \\
1 \text { year to less than } 5 \text { years } \\
5 \text { years to less than } 10 \text { years } \\
10 \text { years or above }\end{array}$ & $\begin{array}{c}0 \\
31 \\
79 \\
56\end{array}$ & $\begin{array}{c}0 \\
18.7 \\
47.6 \\
33.7 \\
\end{array}$ \\
\hline Education level & $\begin{array}{l}\text { No formal qualifications } \\
\text { Non graduate } \\
\text { Graduate } \\
\text { Postgraduate }\end{array}$ & $\begin{array}{c}31 \\
106 \\
25 \\
4 \\
\end{array}$ & $\begin{array}{c}18.7 \\
63.9 \\
15.1 \\
2.4 \\
\end{array}$ \\
\hline Ethnic Background & $\begin{array}{l}\text { Malay } \\
\text { Chinese } \\
\text { Indian } \\
\text { Others } \\
\end{array}$ & $\begin{array}{l}52 \\
88 \\
16 \\
10 \\
\end{array}$ & $\begin{array}{c}31.3 \\
53.0 \\
9.6 \\
6.0 \\
\end{array}$ \\
\hline Gender & $\begin{array}{l}\text { Male } \\
\text { Female }\end{array}$ & $\begin{array}{c}104 \\
62\end{array}$ & $\begin{array}{l}62.7 \\
37.3 \\
\end{array}$ \\
\hline Age & $\begin{array}{l}18-23 \text { years } \\
24-30 \text { years } \\
31-35 \text { years } \\
36-40 \text { years } \\
41-45 \text { years } \\
46-50 \text { years } \\
51-55 \text { years } \\
\text { Above } 55 \text { years }\end{array}$ & $\begin{array}{c}13 \\
65 \\
56 \\
21 \\
1 \\
4 \\
4 \\
2\end{array}$ & \begin{tabular}{c|}
7.8 \\
39.2 \\
33.7 \\
12.7 \\
.6 \\
2.4 \\
2.4 \\
1.2
\end{tabular} \\
\hline
\end{tabular}

Table 2. Eigenvalues and cumulative percentages of factors

\begin{tabular}{|l|l|l|l|l|l|}
\hline Factors & Y1 & Y2 & Y3 & Y4 & Y5 \\
\hline eigenvalue & 8.291 & 3.258 & 1.917 & 1.495 & 1.273 \\
\hline Contribution percentage (\%) & 21.259 & 10.918 & 7.480 & 5.629 & 4.804 \\
\hline Cumulative percentage (\%) & 21.259 & 32.177 & 39.657 & 45.286 & 50.089 \\
\hline
\end{tabular}


Table 3. Rotated Component Matrix

\begin{tabular}{|c|c|c|c|c|c|c|}
\hline & Component & & & & & alpha \\
\hline & 1 & 2 & 3 & 4 & 5 & \\
\hline bureaucracy & .205 & .437 & -.095 & .029 & -.191 & \\
\hline too many licenses & .121 & .678 & .059 & .028 & .086 & \\
\hline accounting standards & .032 & .668 & .043 & .096 & .073 & \\
\hline Licenses refused & -.061 & .788 & -.056 & -.062 & .217 & \\
\hline public procurement regulations & -.071 & .763 & -.039 & .026 & -.053 & .772 \\
\hline lack of support services & -.004 & .754 & .004 & .142 & -.044 & \\
\hline need for certificates & .053 & .685 & -.020 & .020 & -.233 & \\
\hline lack of market information & -.112 & .531 & -.066 & .122 & -.127 & \\
\hline family labour shortage & -.167 & .025 & .562 & .125 & .028 & \\
\hline limits on fixed term workers & .008 & .010 & .726 & .047 & .036 & \\
\hline lack space & .075 & -.106 & .708 & .151 & .229 & \\
\hline lack capacity & .261 & -.112 & .643 & .104 & .252 & \\
\hline lack management time & .266 & -.049 & .727 & .101 & -.055 & .828 \\
\hline low skill labour & .127 & .079 & .703 & -.024 & -.093 & \\
\hline poor labour relations & .140 & .070 & .639 & .060 & -.196 & \\
\hline high profits tax & .196 & -.015 & -.028 & .185 & .791 & \\
\hline high income tax & .288 & -.016 & .117 & .064 & .812 & \\
\hline lack of market demand & .199 & -.005 & .113 & .194 & .455 & .770 \\
\hline access raw materials & .134 & .098 & .079 & .411 & .468 & \\
\hline high collateral requirements & 679 & -.030 & .128 & .322 & .224 & \\
\hline bank charges & .801 & -.026 & .109 & .074 & .198 & \\
\hline bank bureaucracy & .795 & -.040 & .099 & .000 & .007 & \\
\hline banks ignore loan & .775 & .026 & .042 & .023 & .027 & \\
\hline long time to get loan & .691 & -.013 & .110 & .060 & .234 & .892 \\
\hline cost prepare business plan & .496 & -.049 & .081 & -.092 & .281 & \\
\hline refusal of bank finance & .605 & .113 & -.011 & .304 & .125 & \\
\hline lack of state support & .091 & .121 & -.009 & .599 & .142 & \\
\hline lack of support from & .118 & -.016 & .154 & .418 & -.054 & \\
\hline $\begin{array}{l}\text { lack support form business } \\
\text { association }\end{array}$ & .174 & -.065 & .106 & .593 & .065 & \\
\hline lack of consultancy services & .045 & .102 & .137 & .737 & .148 & \\
\hline lack of trust in society & .039 & .087 & .152 & .691 & .121 & .778 \\
\hline
\end{tabular}

Extraction Method: Principal Component Analysis. Rotation Method: Varimax with Kaiser Normalization. A Rotation converged in 5 iterations. 